http://dx.doi.org/10.21707/gs.v11.n03a05

\title{
Diversidade de Blastocladiomycota e Chytridiomycota (Fungi) no rio Poti, Teresina, Piauí
}

\author{
Nayara Dannielle Costa de Sousa ${ }^{1 *}$, José de Ribamar de Sousa Rocha ${ }^{2}$
}

\begin{abstract}
${ }^{1}$ Discente do Mestrado em Desenvolvimento e Meio Ambiente, PRODEMA, Núcleo de Pesquisa do Trópico Ecotonal do Nordeste - TROPEN, Universidade Federal do Piani, Campus Ministro Petrônio Portella, Av. Universitária, 1310, Ininga, 64049-550, Teresina, Piani, Brasil.

${ }^{2}$ Docente do Departamento de Biologia, Laboratório de Micologia, Centro de Ciências da Natureza e do Mestrado em Desenvolvimento e Meio Ambiente, PRODEMA, Núcleo de Pesquisa do Trópico Ecotonal do Nordeste - TROPEN, Universidade Federal do Piauí, Campus Ministro Petrônio Portella, S/N, Ininga, 64049-550, Teresina, Piauí, Brasil.

* Autorpara correspondência: E-mail:nayaradannielle@gmail.com
\end{abstract}

Recebido em 05 de novembro de 2016. Aceito em 22 de maio de 2017. Publicado em 29 de julho de 2017.

REsumo - Fungos zoospóricos são considerados um grupo que engloba táxons ou linhagens evolutivas diferentes, não sendo um grupo uniforme. A classificação desses organismos inclui o Reino Fungi, com representantes nos filos Chytridiomycota e Blastocladiomycota. O presente estudo foi realizado com o objetivo de inventariar a diversidade de Blastocladiomycota e Chytridiomycota no rio Poti, perímetro urbano de Teresina, Piauí, no período de Agosto/13 a Agosto/14. Foram realizadas sete coletas bimestrais de amostras de solo e de água em seis pontos distribuídos às margens do rio. O isolamento desses organismos foi pela técnica de iscagem múltipla com colonização de iscas celulósicas, quitinosas e queratinosas, sendo identificados 21 táxons. Dos táxons obtidos, quatro são pertencentes ao Filo Blastocladiomycota e 17 ao Filo Chytridiomycota.

Palavras-chaves: Fungos Zoospóricos; Diversidade; Fungos Aguáticos.

\section{Diversity of Blastocladiomycota and Chytridiomycota (Fungi) on Poti river, Teresina, Piauí State}

Abstract - Zoosporic fungi are considerate a group, that involve different taxa of evolutionary lineage, not being considered a uniform group. This organism classification includes the Fungi, represented by both phylum Chytridiomycota and Blastocladiomycota. This study has as main objective to inventory the taxa diversity of Blastocladiomycota and Chytridiomycota on Poti River, Teresina urban surroundings from August/13 to August/14. There were made seven samplings, water and soil, each two months, by the Poti river's margin in six differentes points. The microorganisms were isolated, using a multiple bait technique that consists on a colony of multiple cellulosic, chitinous and keratinous baits. This isolation enabled the identification of 21 taxa: four belongs to Blastocladiomycota and 17 to Chytridiomycota.

Keywords: Zoosporic Fungi; DiVErsity; AQuatic FungI.

Diversidad de Blastocladiomycota y Chytridiomycota (Fungi) en el río Poti, Teresina, Piauí

RESumen - Los hongos zoospóricos son considerados un grupo que incluye taxones o linajes evolutivos diferentes, no conformando un grupo uniforme. La clasificación de estos organismos incluye el Reino Fungi, con representantes en los filos Chytridiomycota y Blastocladiomycota. El presente estudio fue realizado con el fin de inventariar la diversidad de Blastocladiomycota y Chytridiomycota en el río Poti, zona urbana de Teresina, Piauí, en el período de Agosto/13 a Agosto/14. Fueron realizadas siete recolecciones bimestrales de muestras de suelo y de agua en seis puntos distribuidos en los márgenes del río. El aislamiento de estos organismos fue por la técnica de cebado múltiple con colonización de cebos celulósicos, quitinosos y queratinosos, siendo identificados 21 taxones. De los taxones obtenidos, cuatro son 
pertenecientes al Filo Bastocladiomycota y 17 al Filo Chytridiomycota.

Palabras claves: Hongos Zoospóricos; Diversidad; Hongos Acuáticos.

\section{INTRODUÇÃO}

Fungos zoospóricos são considerados um grupo de organismos, que englobam táxons ou linhagens evolutivas diferentes, não são taxonomicamente um grupo uniforme. No Brasil, tem-se em média 348 táxons relatados desses organismos, sendo 111 pertencentes ao filo Chytridiomycota e 17 ao filo Blastocladiomycota, pertencentes ao Reino Fungi (Steciow et al. 2012, Maia et al. 2015).

Os fungos zoospóricos pertencentes ao filo Chytridiomycota são semelhantes aos fungos superiores por terem similaridade na composição da parede celular, a bioquímica e análises similares em genética molecular (Pires-Zottarelli e Gomes 2007). Estes organismos estão presentes em uma grande variedade de ecossistemas, vivendo com nutrição saprobionte ou como parasitas de diversos organismos como algas, anfíbios, outros fungos, animais e plantas superiores. O conhecimento de aspectos do ciclo de vida tem permitido novas aplicações de determinadas espécies de fungos zoospóricos. O gênero Olpidium, considerado um vetor de viroses fitopatogênicas, está sendo utilizado na biologia molecular, compostagem e em outras técnicas para eliminação da doença nas plantas (Aguilar et al. 2010, Ohki et al. 2010). Recentemente, Batrachochytridium dendrobatidis Long core (Chytridiomycota) tem sido apontada como responsável pela diminuição da população de anfíbios nativos em várias partes do mundo, inclusive com registros no Brasil, no cerrado e no pantanal (Carnaval et al. 2005, Toledo et al. 2006). Até recentemente, B. dendrobatidis era a única espécie conhecida de fungos verdadeiros a causar doença num hospedeiro vertebrado levando a alta mortalidade. Martel et al. (2013) descreveram uma segunda espécie, Batrachochytrium salamandrivorans, que causou quitridiomicose em salamandras e está implicado no declínio da população de salamandras-de-fogo (Salamandra salamandra).

Blastocladiomycota é um grupo de fungos zoospóricos onde os gênerosformam um grupo monofilético baseados na filogenia do DNA ribossomal e se distinguem de outros grupos de fungos por apresentarem alternância de gerações haplóides e diplóides na reprodução e pela estrutura de seus zoósporos uni flagelados,como ocorre no gênero Allomyces (Porter et al. 2011, James et al. 2014).

Os fungos zoospóricos predominam em ecossistemas aquáticos continentais. Neste contexto, os rios assumem grande importância na diversidade desses organismos. O rio Poti, maior afluente da bacia do Parnaíba, tem grande influência na vivência da população teresinense, a cidade está em crescimento acelerado e este vem ocorrendo de forma desorganizada. Com isso, observa-se o impacto diante da qualidade das águas do rio dentro do perímetro urbano na cidade de Teresina, Piauí, onde no período de estiagem apresenta forte eutrofização, afetando assim, a ecologia do rio e sua microbiota e, provavelmente, a comunidade de fungos zoospóricos e sua ação no ambiente. O conhecimento da diversidade desses organismos é importante para a conservação ambiental desse ecossistema.

Este estudo foi realizado com objetivo de inventariar a diversidade de fungos zoospóricos representantes dos filos Blastocladiomycota e Chytridiomycota no rio Poti, no perímetro urbano de Teresina, Piau.

\section{Material e Métodos}


Area de estudo

A cidade de Teresina, capital do estado do Piauí, localiza-se na faixa de transição entre o semiárido nordestino e a região amazônica, encontra-se a $350 \mathrm{~km}$ do litoral, sendo a única capital do país que se limita com o estado do Maranhão, por meio do rio Parnaíba (Prefeitura Municipal de Teresina 2010). Segundo a Secretaria do Meio Ambiente e Recursos Hídricos do Piauí (2004) a maior densidade demográfica da bacia do rio Poti está na cidade de Teresina.

\section{Coleta de campo}

Foram realizadas coletas bimestrais no rio Poti no período de Agosto/2013 a Agosto/2014, totalizando sete coletas, em seis pontos distribuídos às margens do rio, no perímetro urbano de Teresina até a foz, no encontro com o Rio Parnaíba (Figura 1).

As amostras de água foram coletadas com auxílio de frascos de vidro de boca larga com tampa (250 ml) esterilizada, cerca de $10 \mathrm{~cm}$ abaixo da lâmina de água. As amostras de solo (200 g) foram acondicionadas em sacos plásticos identificados com os pontos de coleta, retiradas à margem do rio, aprofundando $15 \mathrm{~cm}$ com o auxílio de uma espátula e armazenadas em sacos plásticos devidamente identificados com os respectivos pontos de coletas. No momento da coleta foi medida a temperatura do solo e água.

Figura 1 - Localização dos pontos de coleta no rio Poti, perímetro urbano de Teresina - Piauí.
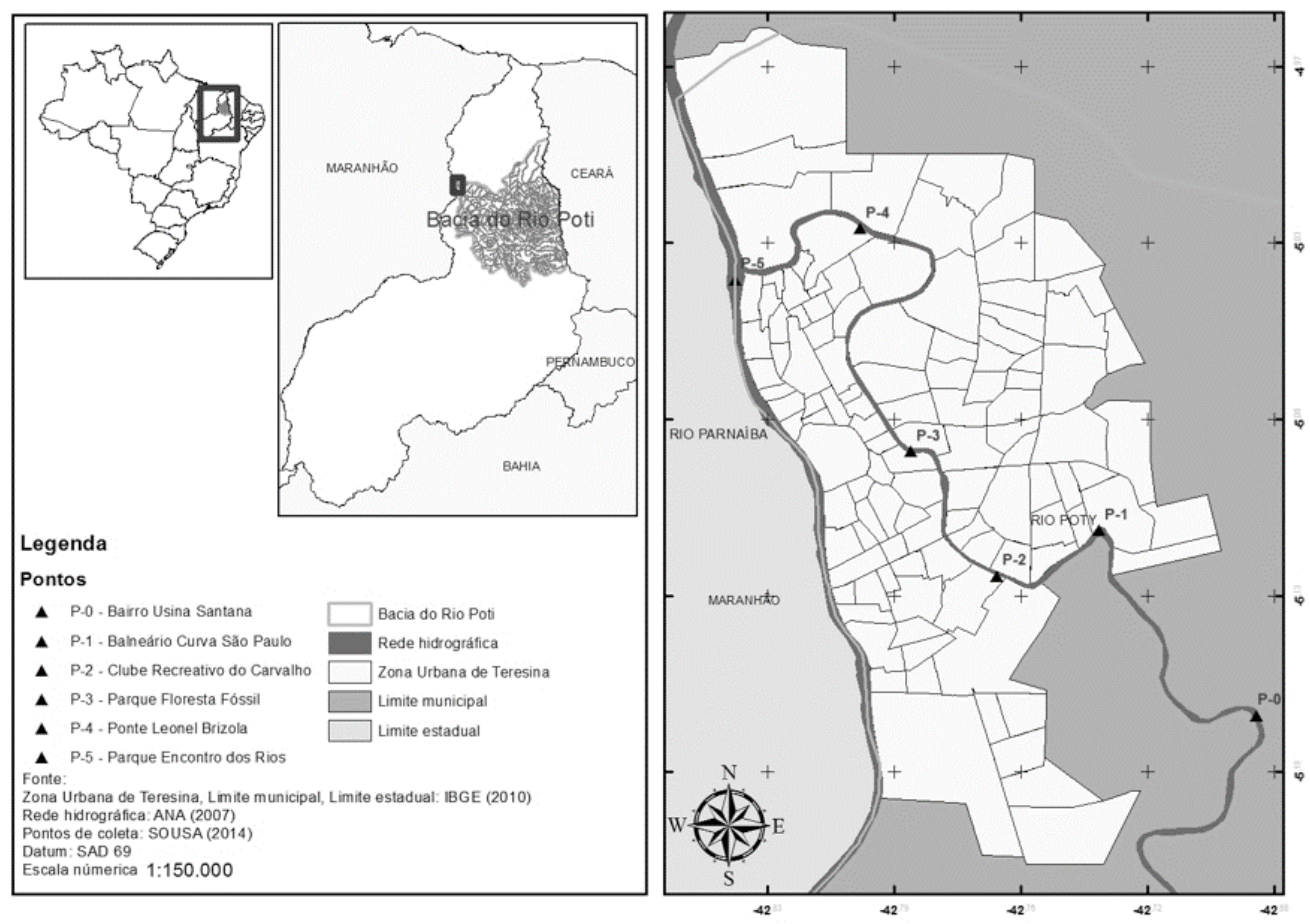

Isolamento e identificação dos táxons

Para o isolamento dos táxons de Blastocladiomycota e Chytridiomycota foi utilizada a técnica de iscagem múltipla (Milanez 1989). Utilizaram-se $50 \mathrm{ml}$ de água para as análises, e acrescentaram-se às placas de petri com água os substratos quitinosos, queratinosos e celulósicos. Para as amostras de solo, foram utilizados $20 \mathrm{~g}$ do 
material com acréscimo de água destilada esterilizada (ADE) e adicionaram-se os substratos. Em seguida, as placas com as amostras foram incubadas em temperatura ambiente $\left(30^{\circ} \mathrm{C}-32^{\circ} \mathrm{C}\right)$, por sete dias.

As observações das estruturas vegetativas e de reprodução foram feitas por meio de microscópio óptico (Olympus BX-41). A identificação dos organismos foi através da literatura especializada. As linhagens selecionadas foram incluídas na coleção de culturas do Laboratório de Fungos Zoospóricos da Universidade Federal do Piauí.

\section{Análise estatística dos táxons}

Os táxons foram considerados como presentes em cada unidade amostral se ocorressem durante a incubação de 4-30 dias nas iscas. Cada unidade amostral consiste em uma placa de Petri com água ou solo do rio com iscas. A abundância (A) dos táxons foi determinada por meio do cálculo do número de ocorrências com base na presença ou ausência do táxon em cada tipo de isca (Letcher e Powell 2001; Marano et al. 2008; Nascimento e Pires-Zottarelli 2009).

A frequência de ocorrência mensal (F) foi calculada de acordo número de unidades amostrais colonizadas pelo táxon/número de unidades amostrais examinadas x 100, onde cada mês foi considerado uma unidade amostral (Zak e Willig 2004). Segundo a escala de frequência de Braun-Blanquet, os táxons encontrados foram classificados em cinco grupos: ubíquos (80,1-100\%); comuns (60,1-80\%); frequentemente presentes (40,1-60\%); escassas (20,1-40\%) e raras (0,1-20\%) (Letcher e Powell 2001, 2002; Marano et al. 2008).

\section{Resultados e Discussão}

Foram identificados 21 táxons, sendo quatro pertencentes ao Filo Blastocladiomycota e 17 ao Filo Chytridiomycota. Blastocladiomycota foi representado por uma ordem (Blastocladiales) e duas famílias (Blastocladiaceae e Catenariaceae). Chytridiomycota apresentou três ordens (Chytridiales, Monoblepharidales, Rhizophlyctidales) e sete famílias (Chytridiaceae, Cladochytriaceae, Nowakowskiellaceae, Septochytriaceae, Endochytriaceae, Gonapodyaceae e Rhizophlyctidaceae). As espécies Catenaria anguillulae Sorokīne e Monoblepharis ovigera Lagerh são as primeiras citações para o Piauí. Os táxons foram descritos, comentados e ilustrados.

\section{REINO FUNGI}

\section{BLASTOCLADIOMYCOTA}

\section{BLASTOCLADIALES}

\section{BLASTOCLADIACEAE}

Allomyces arbusculus E. J. Butler, Ann. Bot., Lond. 25: 1027 (1911) emend. Hatch., J. Elisha Mitchell Sci. Soc. 49(1): 163.1933.

Figura $2 \mathrm{a}-\mathrm{b}$

Descrição: Rocha et al. 2016

Distribuição geográfica no Brasil: Paraíba, Piauí, São Paulo, Rio Grande do Sul.

Material examinado: BRASIL, PIAUÍ. Rio Poti, perímetro urbano de Teresina - PI em amostras de solo nos pontos S2/1.2013 e S5/5.2014.

Comentários: Os dados concordam com a descrição de Pires-Zottarelli (1999) e isolados de Rocha (2002) 
no Piauí. A espécie Allomyces arbusculus foi isolado apenas em amostras de solo. E foi observado em estágio de esporo de resistência concordando com os dados de Rocha et al. (2016).

Allomyces moniliformis Coker \& Braxton, J. Elisha Mitchell scient. Soc.42(1-2): 139 (1926) emend. Emerson, Mycologia 30:127. 1938.

Figura $2 \mathrm{c}$

Descrição: Rocha et al. 2016

Distribuição geográfica no Brasil: Piauí.

Material Examinado: BRASIL, PIAUÍ. Rio Poti, perímetro urbano de Teresina - PI em amostras de solo no ponto S3/3.2013.

Comentários: A primeira citação para o Brasil desta espécie foi encontrada no Parque Nacional de Sete Cidades (Rocha 2002), e desde então não temos registro em outros estados do Brasil (Lista Flora do Brasil 2015). Este isolado do Rio Poti não difere significativamente da descrição de Rocha et al. (2016) e da descrição original, apresentando ápice afilado no esporo de resistência e de tons para o castanho-amarelado.

\section{CATERINACEAE}

Catenophlyctis variabilis (Karling) Karling, American Journal of Botany, 52: 133-138. 1965. Figura 2 e-f

Descrição: Nascimento e Pires-Zottarelli 2010

Distribuição geográfica no Brasil: Amazonas, Minas Gerais, Pernambuco, Piauí, São Paulo.

Material examinado: Brasil, PIAUÍ. Rio Poti, perímetro urbano de Teresina - PI em amostras de solo e água iscadas com ecdise de cobra nos pontos S1/1.2013, A4/1.2013, S3/1.2013, S5/1.2013, S1/2.2013, S2/2.2013, S4/2.2013, A0/2.2013, S0/3.2013, A0/3.2013, S1/3.2013, S1/4.2014, S2/4.2014, S4/4.2014, A3/4.2014, S0/5.2014, A0/5.2014, S0/6.2014, S1/6.2014, S4/6.2014, A1/6.2014, S0/7.2014, S2/7.2014, S3/7.2014, $\mathrm{S} 5 / 7.2014, \mathrm{~A} 0 / 7.2014$.

Comentários: A espécie concorda com a descrição original de Karling (1965). Houve crescimento observado somente em substrato queratinosos de ecdise de cobra concordando com Rocha (2002), Nascimento e Pires-Zottarelli (2012) e mais recentemente com Trindade Jr. (2013) em isolados do Parque Lagoas do Norte, Teresina - PI.

Catenaria anguillulae Sorokīn, Annls Sci. Nat., Bot., sér. 64: 67 (1876).

Figura $2 \mathrm{f}$

Descrição: Pires-Zottarelli 1999

Distribuição geográfica no Brasil: Rondônia, São Paulo.

Material Examinado: BRASIL, PIAUÍ. Rio Poti, perímetro urbano de Teresina - PI em amostras de solo do ponto S4/3.2013 iscadas em ecdise de cobra.

Comentários: O espécime isolado apresentou zoosporângios em tamanhos semelhantes com a descrição de Sparrow (1960) que cita zoosporângio subpiriformes. Pires-Zottarelli (1999) cita zoosporângios esféricos e não foi observado esporo de resistência. A primeira descrição da espécie para o Brasil foi feita por Karling (1946) em Porto Velho, Rondônia. A espécie pode ser a primeira citação para o Piauí. 
Figura 2 - Blastocladiomycota do rio Poti, perímetro urbano de Teresina, Piauí, Brasil. a-b. Allomyces arbusculus E. J. Butler. Esporo de resistência castanho, zoosporângio cheio e vazio; c. Allomyces moniliformis Coker \& Braxton. Esporo de resistência; d-e. Catenophlyctis variabilis Karling (Karling). Zoosporângios com talo policêntrico; f. Catenaria anguillulae Sorokin. Zoosporângios com talo policêntrico. Barras: $10 \mu \mathrm{m}$.
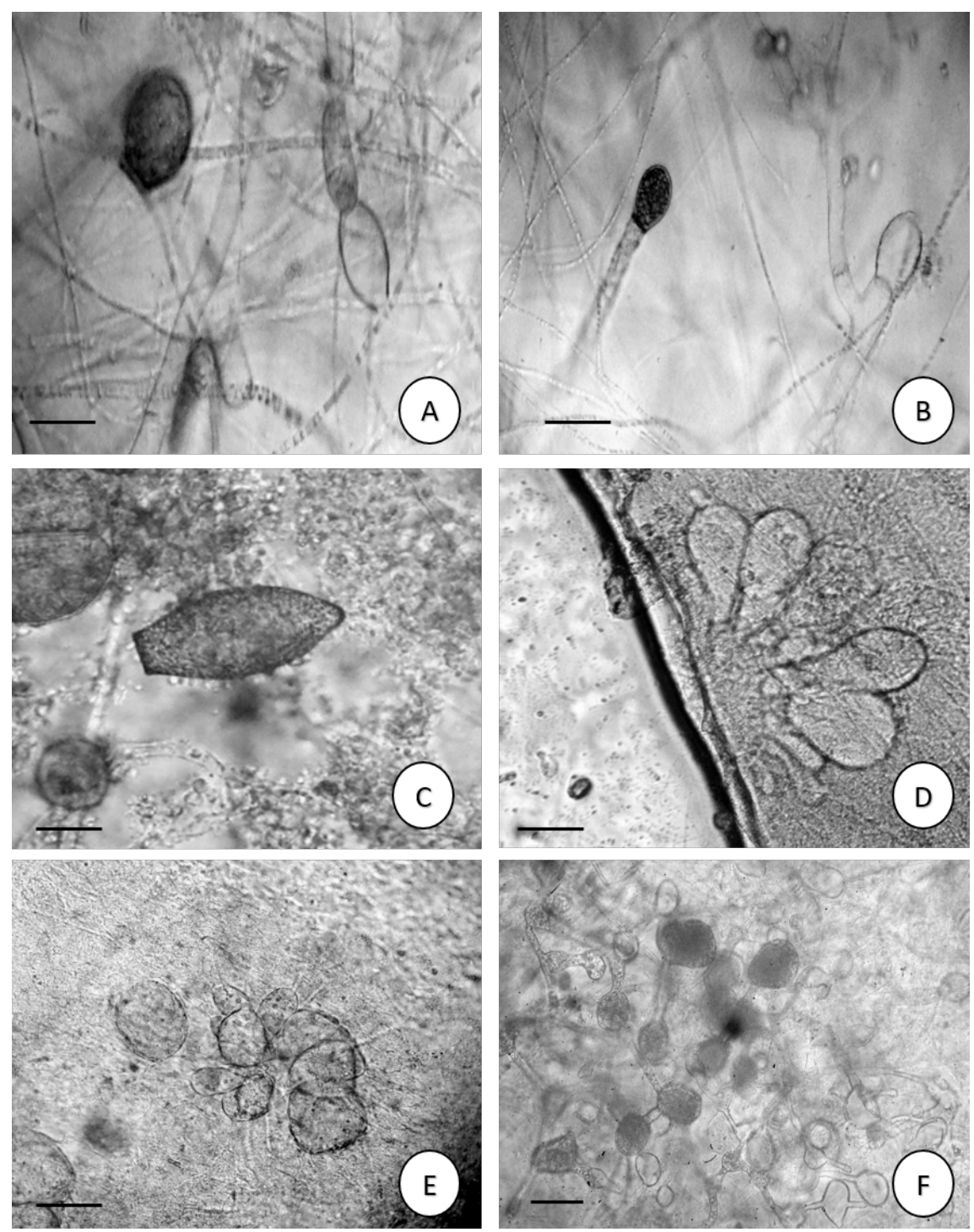

\section{CHYTRIDIOMYCOTA}

\section{CHYTRIDIALES}

\section{CHYTRIDIACEAE}

Cylindrochytridium johnstonii Karling, Bull. Torrey Bot. Club. 68:383. 1941.

Figura 3 a

Descrição: Rocha e Pires-Zottarelli 2002

Distribuição geográfica no Brasil: Pernambuco, São Paulo.

Material examinado: BRASIL, PIAUÍ. Rio Poti, perímetro urbano de Teresina - PI em amostras de água no ponto A3/1.2013 e em amostras de solo no ponto S2/7. 2014.

Comentários: A espécie descrita concorda com a descrição original de Karling (1941). Concordando também com Rocha e Pires-Zottarelli (2002) onde também isolaram a espécie em substratos celulósicos e apenas em amostras de água. 
Karlingiomyces granulatus (Karling) Sparrow, Aquatic Phycomycetes, Edn 2 (Ann Arbor): 563 (1960)

Figura $3 \mathrm{~b}$

Descrição: Nascimento e Pires-Zottarelli 2010

Distribuição geográfica no Brasil: Amazonas, Rondônia, Minas Gerais, São Paulo.

Material examinado: BRASIL, PIAUÍ. Rio Poti, perímetro urbano de Teresina - PI em amostras de solo e água nos pontos S3/1.2013, A2/3.2013, A4/4.2014, S0/6.2014 e S5/6.2014.

Comentários: São características desta espécie zoosporângios com parede lisa, mas tornando-se enrugada com coloração acinzentada. A espécie colonizou substratos celulósicos como papel celofane e palha de milho, concordando com a descrição original de Karling (1947), Rocha; Pires-Zottarelli (2002) e Nascimento; PiresZottarelli (2012) que também registraram a espécie apenas em substratos celulósicos.

\section{CLADOCHYTRIACEAE}

Cladochytrium replicatum Karling, Am. J. Bot. 18(7): 538 (1931).

Figura $3 \mathrm{c}-\mathrm{d}$

Descrição: Nascimento e Pires-Zottarelli 2009

Distribuição geográfica no Brasil: Acre, Amazonas, Rondônia, Ceará, Pernambuco, Piauí, Minas Gerais, São Paulo.

Material examinado: BRASIL, PIAUÍ. Rio Poti, perímetro urbano de Teresina - PI em amostras de solo e água nos respectivos pontos A2/1.2013, S3/1.2013, A4/1.2013, A5/1.2013, S4/1.2013, A1/2.2013, S2/2.2013, S3/2.2013, A3/2.2013, A1/3.2013, A2/3.2013, A3/4.2014, A4/4.2014, S1/5.2014, S4/5.2014, A1/5.2014, S1/6.2014, S2/6.2014, A1/6.2014, A2/6.2014, A3/6.2014, A5/6.2014, A0/7.2014, A1/7.2014 e A2/7.2014.

Comentários: As características do isolado concordam com Sparrow (1960) e Karling (1977), além de concordar com Rocha e Pires-Zottarelli (2002), Rocha (2002), Pires-Zottarelli e Gomes (2007) e Nascimento (2010).

Cladochytrium setigerum Karling, Bull. Torrey bot. Club 78(1): 38 (1951).

Figura 3 e-f

Descrição: Nascimento e Pires-Zottarelli 2009

Distribuição geográfica no Brasil: São Paulo

Material examinado: BRASIL, PIAUÍ. Rio Poti, perímetro urbano de Teresina - PI em amostra de água no ponto A5/6.2014.

Comentários: Concorda com a descrição de Nascimento e Pires-Zottarelli (2009), o qual acrescenta que os esporos de resistência são intercalares, variáveis em forma. Foi isolado em amostras de água colonizando epiderme de cebola no Parque Estadual da Serra da Cantareira, São Paulo como a primeira citação para o Brasil. Este isolado do rio Poti, pode ser destacado como um importante relato da espécie para o Piauí. 
Figura 3 - Chytridiomycota do rio Poti, perímetro urbano de Teresina, Piauí, Brasil. a. Cylindrochytridium johnstonii Karling. Zoosporângios cheios; b. Karligiomyces granulatus Karling. Zoosporângio com rizoides constrictos. c-d. Cladochytrium replicatum Karling. c. Zoosporângio com oósporos alaranjados; d. esporo de resistência âmbar; e-f. Cladochytrium setigerum Karling. e. Esporo de resistência ornamentado; f. células turbinadas. Barras: $10 \mu \mathrm{m}$.
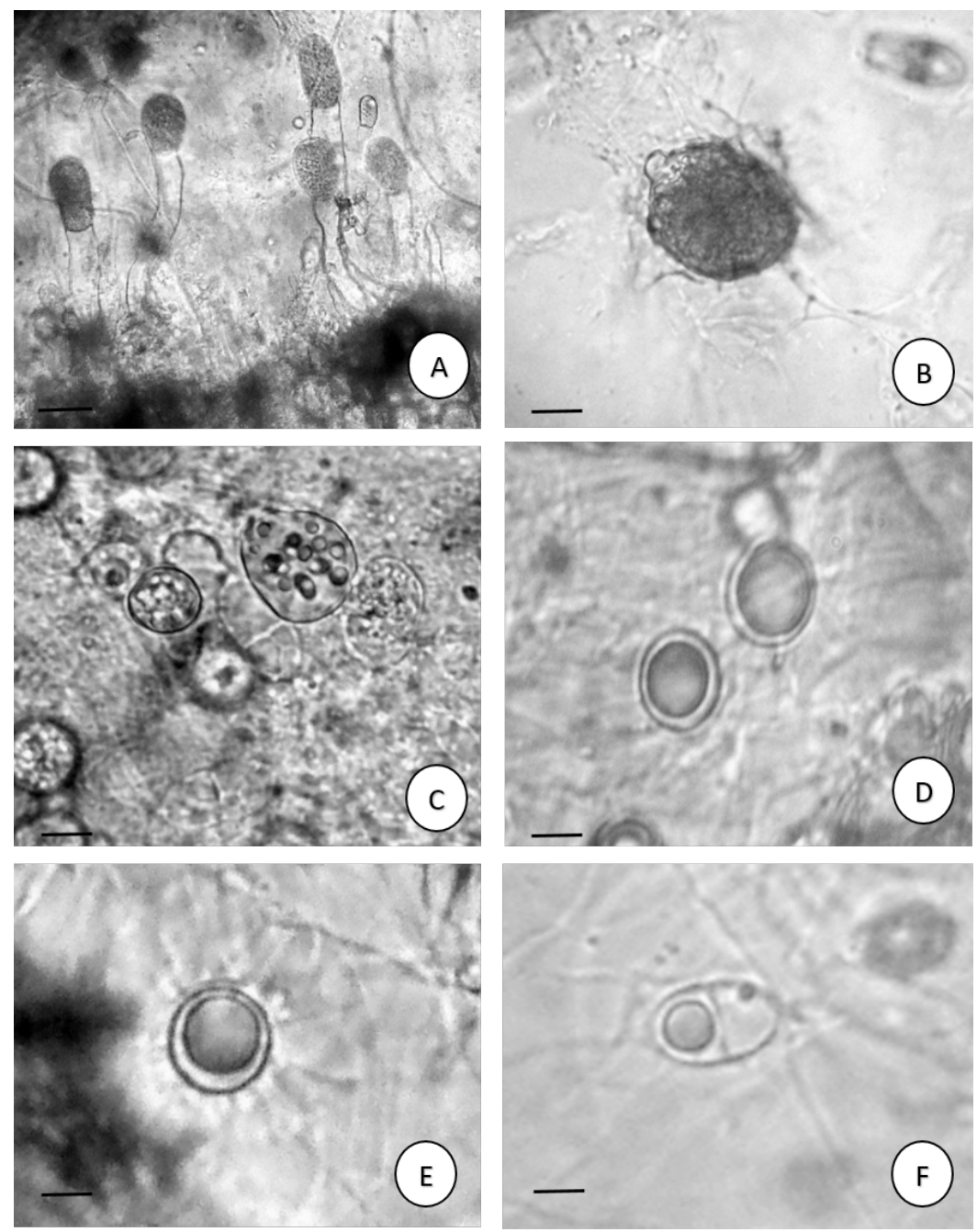

Polychytrium aggregatum Ajello, Mycologia, 34(4): 442. 1942.

Figura 4 a

Descrição: Pires-Zottarelli e Gomes 2007.

Distribuição geográfica no Brasil: Amazonas, Piauí, São Paulo.

Material examinado: BRASIL, PIAUÍ. Rio Poti, perímetro urbano de Teresina - PI em amostras de água no ponto A2/3.2013.

Comentários: Os dados se assemelham a descrição de Rocha (2002), concordando ainda com a descrição de Pires-Zottarelli e Gomes (2007), Nascimento e Pires-Zottarelli (2012), além de concordar com a descrição original de Ajello (1942).

\section{NOWAKOWSKIELLACEAE}

Nowakowskiella elegans (Nowak.) Schroeter, Engler and Prantl, Naturlichen Pfanzenfamilien 1: 82.1892 (18 93).

Figura $4 \mathrm{~b}$ 
Descrição: Nascimento e Pires-Zottarelli 2009.

Distribuição geográfica no Brasil: Amazonas, Rondônia, Paraíba, Piauí, Pernambuco, São Paulo.

Material examinado: BRASIL, PIAUÍ. Rio Poti, perímetro urbano de Teresina - PI em amostras de solo e água nos respectivos pontos S2/1.2013, A4/1.2013, A5/1.2013, S2/2.2013, S5/2.2013, A2/5.2014, S2/3.2013, A3/3.2013, S4/5.2014, A1/5.2014, S1/6.2014, S2/6.2014, A1/6.2014, A2/6.2014, A3/6.2014, A5/6.2014, A0/7.2014, A1/7.2014, A2/7.2014.

Comentários: Os dados analisados concordam com a descrição original de Sparrow (1960), Milanez (1984), Pires-Zottarelli (1999) e Rocha (2002). Os isolados apresentam zoosporângios e zoósporos com dimensões maiores dos que os citados por Pires-Zottarelli et al. (1996). Não foi observado esporo de resistência nestes isolados, concordando com a descrição de Trindade Jr. (2013) no Parque Lagoas do Norte, Teresina - PI.

Nowakowskiella elongata Karling, Bull. Torrey bot. Club 71: 375 (1944).

Figura $4 \mathrm{c}$

Descrição: Jesus et al. 2013.

Distribuição geográfica no Brasil: Amazonas, Rondônia, Piauí, Mato Grosso do Sul, São Paulo.

Material examinado: BRASIL, PIAUÍ. Rio Poti, perímetro urbano de Teresina - PI em amostras de solo e água nos respectivos pontos S3/3.2013 e A2/5.2014.

Comentários: As características dos espécimes concordam com as descritas por Karling (1944). Neste estudo, a espécie isolada teve desenvolvimento em substratos celulósicos tais como palha de milho e epiderme de cebola em amostras de solo e água. A espécie aqui descrita concorda com os espécimes isolados por Rocha (2002) e mais, recentemente, com Jesus et al. (2013) que citam o crescimento somente em epiderme de cebola.

Nowakowskiella hemiphaerospora Shanor, Am. J. Bot. 29: 174. 1942.

Figura $4 \mathrm{~d}$

Descrição: Pires-Zottarelli 1999

Distribuição geográfica no Brasil: Minas Gerais, São Paulo, Piauí.

Material examinado: BRASIL, PIAUÍ. Rio Poti, perímetro urbano de Teresina - PI em amostras de solo e água nos respectivos pontos S4/1.2013 e A5/1.2013.

Comentários: Esta espécie tem como característica marcante os esporos de resistência bipartidos. As características gerais estão de acordo com Sparrow (1960), porém o autor cita tamanho diferenciado de

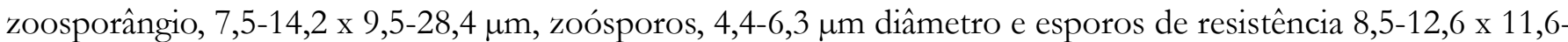
15,6 $\mu \mathrm{m}$. Estes dados também concordam com Pires-Zottarelli (1999) e Trindade Jr. (2013).

\section{SEPTOCHYTRIACEAE}

Septochytrium variabile Berdan, Am. J. of Botany 26: 461, fig.2. 1939.

Figura 4 e-f

Descrição: Pires-Zottarelli e Rocha 2007

Distribuição geográfica no Brasil: Pernambuco, Piauí, Minas Gerais, São Paulo.

Material examinado: BRASIL, PIAUÍ. Rio Poti, perímetro urbano de Teresina - PI em amostras de solo e água respectivamente nos pontos A4/1.2013, S3/2.2013, S2/7.2014, A4/7. 2014. 
Comentários: As principais características desta espécie são a presença de septos ou constrições no rizomicélio, zoosporângios operculados. Concordando com Rocha (2002) encontrou em substratos celulósicos. Porém este espécime isolado do rio Poti teve culturas em crescimento em amostras de solo e água.

Figura 4 - Chytridiomycota do rio Poti, perímetro urbano de Teresina, Piauí, Brasil. a. Polychytrium aggregatum Ajello. Zoosporângio com proliferação interna; b. Nowakowskiella elegans (Nowak.) J.Schröt; Zoosporângio com esporos. c. Nowakowskiella elongata Karling. Zoosporângio com esporos; d. Nowakowskiella hemiphaerospora Shanor. Esporo de resistência

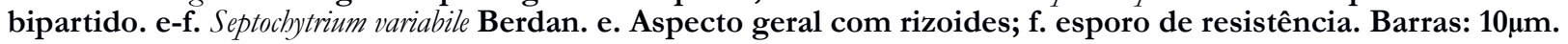
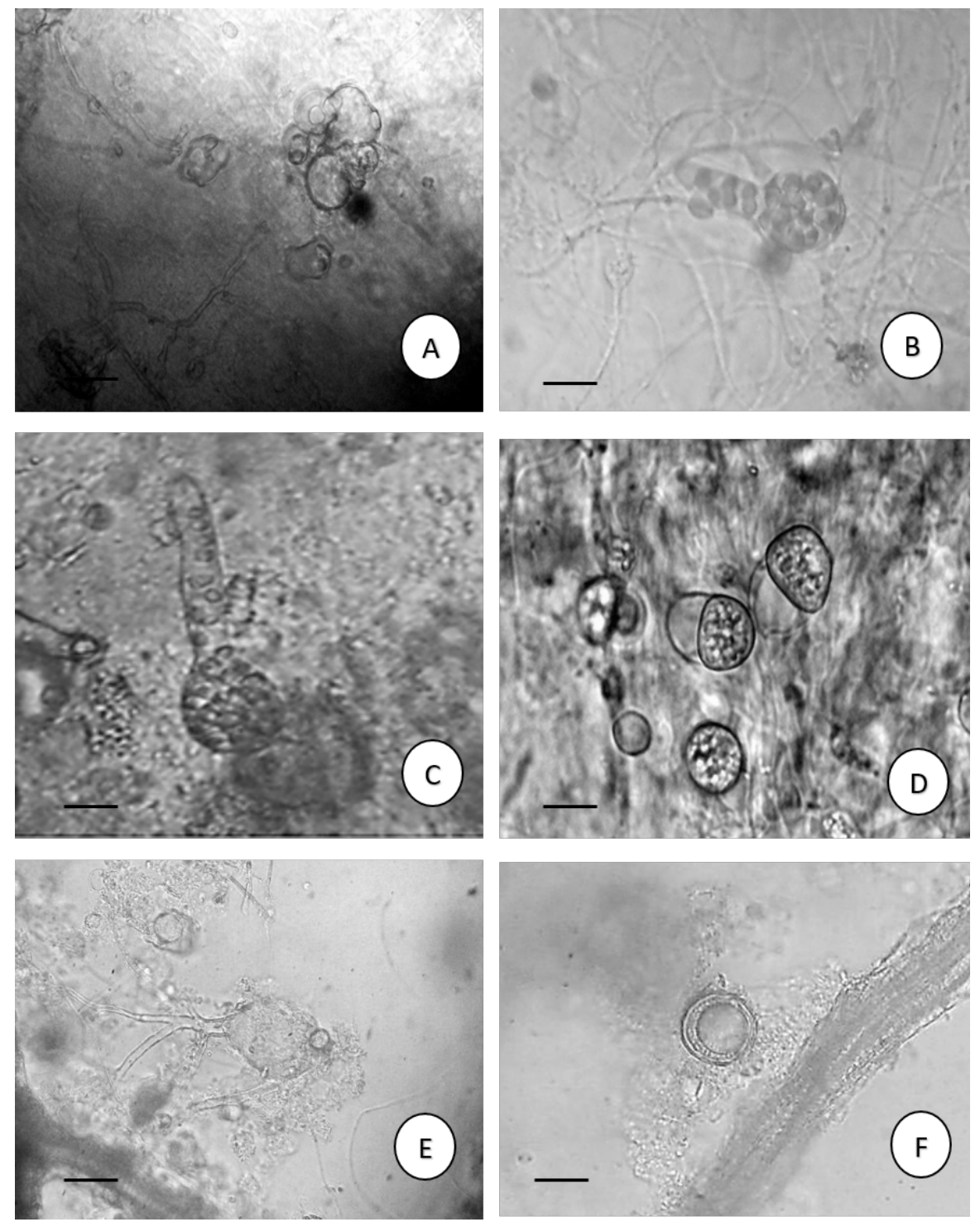

\section{ENDOCHYTRIACEAE}

Asterophlyctis sarcoptoides H.E. Petersen, J. Bot., Paris 17: 218 (1903).

Figura $5 \mathrm{a}-\mathrm{b}$

Descrição: Nascimento e Pires-Zottarelli 2009

Distribuição geográfica no Brasil: Amazonas, Piauí, Minas Gerais, São Paulo.

Material examinado: BRASIL, PIAUÍ. Rio Poti, perímetro urbano de Teresina - PI em amostras de água nos pontos A4/1.2013 e A5/1.2013.

Comentários: Os espécimes examinados concordam parcialmente com a descrição original de Dogma 
(1974) que menciona a ocorrência de zoosporângios lisos, não observados neste isolado. Os zoosporângios ovais apresentaram medidas aproximadas de 9-39 x 6-32 $\mu \mathrm{m}$ concordando com Nascimento e Pires-Zottarelli $(2009,2012)$. Neste estudo houve registros de ocorrência em asa de cupim e ecdise de cobra.

Catenochytridium carolinianum Berdan, American Journal of Botany 26: 461. 1939.

Figura $5 \mathrm{c}$

Descrição: Rocha 2002

Distribuição geográfica no Brasil: Piauí.

Material examinado: BRASIL, PIAUÍ. Rio Poti, perímetro urbano de Teresina - PI em amostras de água e solo nos pontos A3/1.2013, S3/1.2013, A1/2.2013 e S2/5.2014.

Comentários: A descrição concorda com os dados da a citação original e com os isolados de Rocha (2002) no Parque Nacional de Sete Cidades, que fez a primeira citação do táxon para o Brasil.

Catenochytridium kevorkianni Sparrow, Rev. Soc. Cubana Bot. 9:70. 1952.

Figura $5 \mathrm{~d}$

Descrição: Rocha 2002

Distribuição geográfica no Brasil: Amazonas, Pernambuco, Piauí, Minas Gerais, São Paulo.

Material examinado: BRASIL, PIAUÍ. Rio Poti, perímetro urbano de Teresina - PI em amostras de água nos pontos A1/1.2013, A4/5.2014, A5/6.2014.

Comentários: As características concordam em parte com descrição original de Sparrow (1952), sendo que não houve a observação do esporo de resistência. Rocha (2002) observou esporos de resistência hialinos a âmbar-claro e também isolou apenas em amostras de água. Pires-Zottarelli (1999) descreveu esporos de resistência semelhantes ao deste isolado.

\section{MONOBLEPHARIDALES}

GONAPODYACEAE

Gonapodya polymorpha Thaxter, Bot. Gaz. 20:481. 1895.

Figura 5 e

Descrição: Rocha 2002

Distribuição geográfica no Brasil: Amazonas, Piauí, Minas Gerais, São Paulo.

Material examinado: BRASIL, PIAUÍ. Rio Poti, perímetro urbano de Teresina - PI em amostras de água no ponto A4/5.2014.

Comentários: As características assemelham com as citadas na descrição original, além de concordar com os achados de Milanez (1984) e mais recentemente com os relatos do espécime isolado por Trindade Jr. (2013) em lagoas do Norte de Teresina - PI. Rocha (2002) relata a observação dos órgãos sexuais.

Globisporangium proliferum (Cornu) P.M. Kirk, Index Fungorum 191: 1 (2014).

Figura $5 \mathrm{f}$

Descrição: Pires-Zottarelli e Gomes 2007

Distribuição geográfica no Brasil: Amazonas, Piauí, Minas Gerais, São Paulo. 
Material examinado: BRASIL, PIAUÍ. Rio Poti, perímetro urbano de Teresina - PI em amostras de água nos pontos A0/3.2013 e A4/5.2014 e no ponto de solo S5/3.2013.

Comentários: Esta espécie foi isolada em amostras de solo e água e concordam com a descrição feita por Rocha (2002). Os relatos feitos por Pires-Zottarelli; Gomes (2007), Nascimento; Pires-Zottarelli (2012) e Trindade Jr. (2013) se assemelham também com esta descrição, além de concordar com a descrição de Karling (1977).

Figura 5 - Chytridiomycota do rio Poti, perímetro urbano de Teresina, Piauí, Brasil. a-b. Asterophlyctis sarcoptoides (H.E.Petersen) Dogma. Aspecto geral do zoosporângio; c. Catenochytridium carolinianum Berdan. Zoosporângio vazio com opérculo. d. Catenochytridium kevorkianni Sparrow. Zoosporângio vazio com rizoides catenulados. e. Gonapodya polymorpha Thaxter. Aspecto geral do zoosporângio. f. Globisporangium proliferum (Cornu) P.M. Kirk. Aspecto geral do zoosporângio com proliferação interna. Barras: $10 \mu \mathrm{m}$.
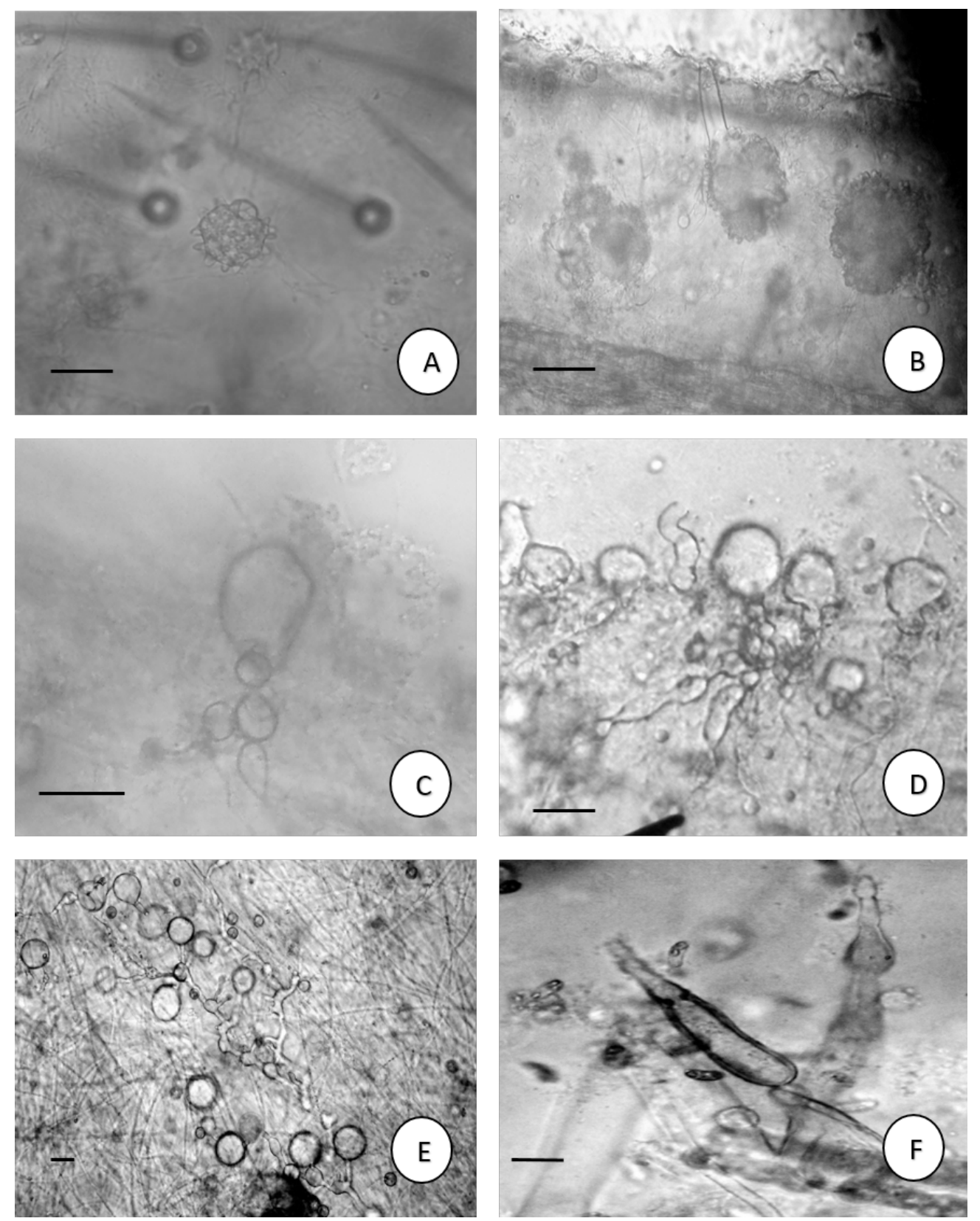

Monoblepharella taylorii (Sparrow) Sparrow, Allan Hancock Found. Publ., Occass. Pap., Ser. 1 3(6): 103 (1940).

Figura 6 a-b 
Descrição: Rocha et al. 2015

Distribuição geográfica no Brasil: Piauí, Maranhão.

Material examinado: BRASIL, PIAUÍ. Rio Poti, perímetro urbano de Teresina - PI em amostras de solo e água nos respectivos pontos S3/1.2013, S2/7.2014, S3/7.2014 e A3/7.2014.

Comentários: A descrição dos isolados concordam com a descrição original de Sparrow (1940). Monoblepharella mexicana Shanor era a única espécie do gênero referida para o Brasil, ocorrida em amostras de solo do estado de São Paulo (Joffily 1947), até a publicação de Rocha et al. (2015) de Monoblepharella taylorii como primeiro registro para o Brasil.

\section{MONOBLEPHARIDACEAE}

Monoblepharis ovigera Lagerh., Bih. K. svenskaVetensk Akad.Handl.,Afd. 325 (no. 8): 36 (1899). Figura 6 c-d

Descrição: Micélio frequentemente profuso, composto por delicadas hifas ocasionalmente ramificada,

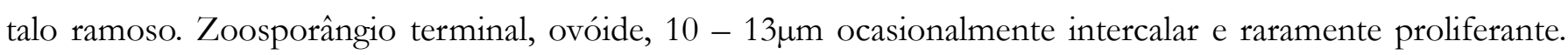
Zoósporos formados em duas fileiras com 8 x $6 \mu \mathrm{m}$ e reprodução sexual não observada.

Distribuição geográfica no Brasil: Piauí

Material examinado: BRASIL, PIAUÍ. Rio Poti, perímetro urbano de Teresina - PI em amostras de solo e água nos respectivos pontos A5/3.2013, S2/7.2014, A4/7.2014 e A5/7.2014.

Comentários: A espécie descrita concorda com a descrição de Sparrow (1960) e tem registro apenas no Piauí.

\section{RHIZOPHLYCTIDALES}

RHIZOPHLYCTIDACEAE

Rhizophlyctis rosea (de Bary \& Woronin) A. Fisch., in Winter, Rabenh. Krypt.-Fl., Edn 2 (Leipzig) 1(4): 122 (1891).

Figura 6 e-f

Descrição: Nascimento e Pires-Zottarelli 2012

Distribuição geográfica no Brasil: Acre, Amazonas, Rondônia, Alagoas, Bahia, Maranhão, Pernambuco, Piauí, Goiás, Mato Grosso do Sul, Minas Gerais, Rio de Janeiro, São Paulo, Paraná, Rio Grande do Sul, Santa Catarina.

Material examinado: BRASIL, PIAUÍ. Rio Poti, perímetro urbano de Teresina - PI em amostras de solo no ponto S2/1.2013, S1/6.2014, S2/7.2014 e S3/7.2014.

Comentários: Concordando com a descrição de Nascimento e Pires-Zottarelli (2012) e Blackwell et al. (2004); a espécie é facilmente identificada pelas suas características de cor arroseada.

\section{OCORRÊNCIA E DISTRIBUIÇÃo DOS TÁXONS}

Observou-se a predominância entre os isolados de Chytridiomycota, com 17 táxons, e quatro táxons representaram Blastocladiomycota (Tabela 1), similarmente com Pires-Zottarelli e Gomes (2007) que isolaram 3 
da ordem blastocladiales e 23 da ordem chytridiales na Reserva Biológica de Paranapiacicaba, Santo André - SP.

Figura 6 - Chytridiomycota do rio Poti, perímetro urbano de Teresina, Piauí, Brasil. a-b. Monoblepharella taylorii (Sparrow) Sparrow. a. Oogônio jovem; b. Zoosporângio maduro; c-d. Monoblepharis ovigera Lagerh. c. Zoosporângio; d. Liberação dos zoósporos. e-f. Rhizophlyctis rosea (De Bary \& Woronin) A.Fisch. Zoosporângios com rizóides e tubo de liberação. Barras: $10 \mu \mathrm{m}$.
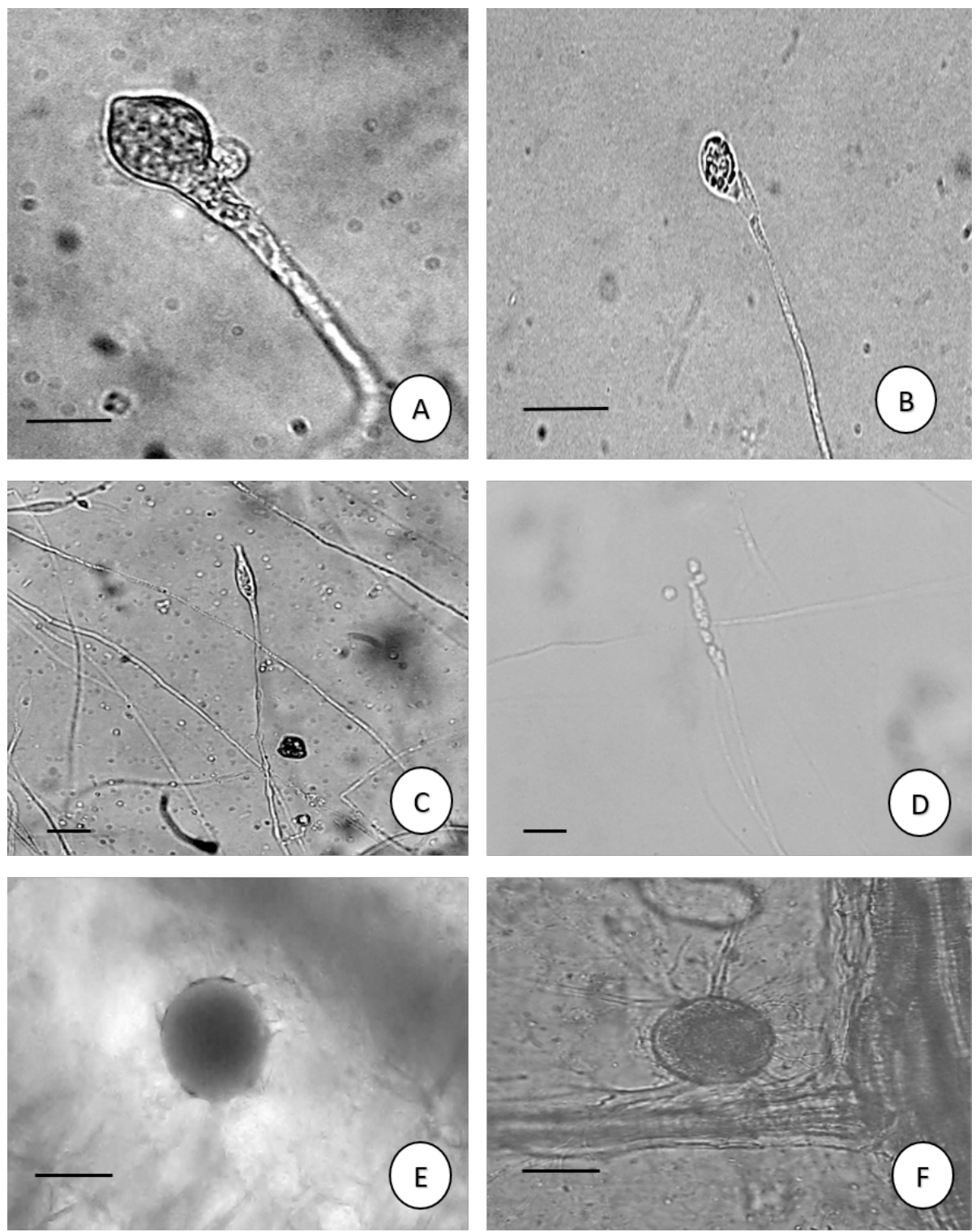

Blastocladiomycota e Chytridiomycota, considerando a classificação de Braun-blanquet em relação à frequência, três táxons foram classificados em ubíquos, sendo que Catenophlyctis variabilis Karling (Karling), Cladochytrium replicatum Karling e Nowakowskiella elegans (Nowak.) J.Schröt estiveram presentes em todas as coletas. O gênero Nowakowskiella é frequentemente encontrado no Piauí, e apesar de ocorrer em outros estados do Brasil, não é um táxon muito comum. Na Argentina foi citado pela primeira vez apenas em 2007 (MARANO et al., 2007).

Ainda segundo a escala de Braun-blanquet, não foram observados táxons relativos à classe comum. Cinco táxons foram considerados frequentemente presentes, Karligiomyces granulatus Karling, Sepctochytrium variabile Berdan, Catenochytridium carolinianum Berdan, Catenocbytridium kevorkianni Sparrow e Rhizophlyctis rosea (De 
Bary \& Woronin) A. Fisch. Dogma. Seis táxons foram considerados escassos, Allomyces arbusculus E.J. Butler, Cylindrochytridium johnstonii Karling, Nowakowskiella elongata Karling, Globisporangium proliferum (Cornu) P.M. Kirk, Monoblepha rella taylorii Sparrow, Monoblepharis ovigera Lagerh. As espécies Allomyces moniliformis Coker\& Braxton, Catenaria anguillulae Sorokin, Cladochytrium setigerum Karling, Asterophlyctis sarcoptoides (H.E.Petersen), Nowakoskiella hemiphaerosphora Shanor, Polychytrium aggregatum Ajello, Gonapodya polymorpha Thaxt. apresentaram frequência de 14,29\% registrando o aparecimento em apenas uma única coleta, sendo táxons raros (Tabela 2).

Considerando a ocorrência nos compartimentos água e solo, alguns táxons ocorreram exclusivamente na água ou no solo. Dos 21 táxons observados, quatro foram restritos a ocorrência em apenas amostras de solo, tais como, Allomyces arbusculus, Allomyces moniliformis, Catenaria anguillulae e Rhizophlyctis rosea. E cinco táxons ocorreram apenas em amostra de água, sendo Cladochytrium setigerum, Asterophlyctis sarcoptoides, Gonapodyapolymorpha, Catenochytridium kervokianni e Polychytrium aggregatum. Esse resultado concorda com os estudos realizados por Shearer et al. (2007), os quais relatam que algumas espécies desses organismos podem ocorrer exclusivamente na água ou no solo. No solo, sendo necessária a existência de apenas um filme de água para que ocorra a disseminação dos zoósporos, característica comum ao grupo, contudo, a maioria das espécies é comum aos dois compartimentos. Jeronimo et al. (2015) realizaram 256 isolamentos, 112 da água e 144 do solo, com a identificação de 34 táxons na Ilha do Cardoso, no estado de São Paulo, indicando uma micota diversa e com poucos táxons dominantes, a maioria presente tanto nas amostras de água como nas de solo.

A abundância das espécies diferiu durante o estudo, na coleta do mês de Fev/14 obteve-se o menor registro do número de táxons. Os maiores registros de riqueza foram nas coletas de Ago/13 e Dez/13. Nascimento et al. (2011) encontraram em seu trabalho espécies de ocorrências exclusivas em algumas áreas e em coletas específicas, condizendo com os resultados deste trabalho para as espécies Allomyces moniliformis Coker \& Braxton, Catenaria anguillulae Sorokin, Cladochytrium setigerum Karling, Asterophlyctis sarcoptoides (H.E.Petersen), Nowakoskiella hemiphaerosphora Shanor, Polychytrium aggregatum Ajello e Gonapodya polymorpha Thaxt.

\section{Agradecimentos}

À Coordenação de Aperfeiçoamento de Pessoal de Nível Superior (CAPES), pela concessão de bolsa à primeira autora. Ao Laboratório de Fungos Zoospóricos da Universidade Federal do Piauí, pela infraestrutura oferecida para o desenvolvimento da pesquisa e seus estagiários pelo apoio nas atividades de laboratório.

\section{REFERÊNCIAS}

Aguilar MI, Guirado ML, Melero-Vara JM and Gómez J. 2010. Efficacy of composting infected plant residues in reducing the viability of pepper mild mottle virus, melon necrotic spot virus and its vector, the soil-borne fungus Olpidium bornovanus. Crop Protection, 29(4):342-348.

Ajello L. 1942. Polychytrium, a new Cladochytriaceous genus. Mycologia, 34:442-451.

Blackwell WH, Letcher PM and Powell MJ. 2004. Synopsis and systematic reconsideration of Karlingiomyces (Chytridiomycota). Mycotaxon, 89: 259-276. 
Carnaval ACOQ, Toledo LF, Haddad CFB; Britto FB.2005. Chytrid fungus infects high altitude stream-dwelling Hylodes magalhaesi (Leptopdactylidade) in the Brazilian Atlantic rainforest. Froglog, 70(3).

Coker WC. 1923. The Saprolegniaceae, with notes on other water moulds. Chapell Hill, the University of North Carolina press, p. 201.

Dogma JR.1974. Studies on Chitinophilicsi phonaria, Asterophlyctis and Rhizoclosmatium, chytridiales. II Asterophlyctis sarcoptoides h. E. Petersen: a Diplophlyctis with a sexual phase. Nova Hedwigia, 25:1-50.

Index fungorum. 2013. <http://www.indexfungorum.org/names/names.asp. Acesso em 24/02/2016>

James, TY, Porter TM, Martin WW. 2014. 7 Blastocladiomycota. In: Systematics and Evolution. Springer berlinheidelberg, p. 177-207.

Jerônimo GH, Jesus ALD, Marano AV, James TY, Souza JID, Rocha SCO and Pires-Zottarelli CLA. 201.Diversity of blastocladiomycota and chytridiomycota from parque estadual da ilha do Cardoso, Cananéia, São Paulo state, Brazil. Hoehnea, 42(1):135-163.

Jesus AL, Marano AV, Schoenlein-Crusius IH and Pires-Zotarelli CLA. 2013. Diversidade de organismos zoospóricos heterotróficos do Parque Estadual das fontes do Ipiranga, São Paulo, SP, Brasil: novas citações. Hoehnea, 40:167-180.

Joffily JM. 1947. Alguns ficomicetos aquáticos e terrícolas do brasil. Boletim da sociedade Brasileira de agronomia, 10(2): 95-113.

Karling JS. 1941. Cylindrochytridium johnstonii gen. Nov. Et sp. Nov., and Nowakowskiella profusum sp. Nov. Bulletin of the Torrey Botanical, 68:381-387.

Karling, JS. 1945. Brazilian chytrids. V. Nowaskowskiella macrospora n. Sp., and other polycentric species. American journal of botany, 32: 29-35.

Karling, JS.1946. Keratinophilic chytrids. American Journal of Botany, 32:219.

Karling JS. 1947. Brazilian chytrids X. New species with sunken opercula. Mycologia, 39: 56-70.

Karling, JS. 1965. Catenophlyctis a new genus of the catenariaceae. American Journal of Botany, 52: 133-138.

Karling JS. 1977. Chytridiomycetarum iconographia. J. Cramer. Vaduz.

Letcher PM and Powell MJ.2001. Distribution of zoosporic fungi in forest soils of the blue ridge and appalachian mountains of virginia. Mycologia, 93: 1029-1041.

Lista de espécies da flora do brasil.2020 em construção. Jardim botânico do Rio de Janeiro. Disponível em: $<$ http://floradobrasil.jbrj.gov.br/>. Acesso em: 13 jan. 2016.

Maia LC, Carvalho Jr A, Cavalcanti LH, Gugliotta AM, Drechsler-Santos ER, Santiago ALMA, Cáceres MES, Ibertoni TB, Aptroot A, Giachini AJ, Soares MAS, Silva ACG, Magnago AC, Goto BT, Lira CRS, Montoya CAS, 
Pires-Zottarelli CLA, Silva DKA, Soares DJ, Rezende DHC, Luz EDMN, Gumboski EL, Wartchow F, Karstedt F, Freire, FM, Coutinho FP, Melo GSN, Sotão HMP, Baseia IG, Pereira J, Oliveira JJS, Souza JF, Bezerra JL, Araujo Neta LS, Pfenning LH, Gusmão LFP, Neves MA, Capelari M, Jaeger MCW, Pulgarín MP, Menolli Jr N, Medeiros OS, Friedrich RS, Chikowski RS, Pires RM, Melo RF, Silveira RMB, Urrea-Valencia S, Cortez VG and Silva VF. 2015. Diversity of brazilian fungi. Rodriguésia, 66(4) :1033-1045.

Marano AV, Steciow MM, Arellano ML, Arambarri AM and Sierra MV. 2007. El género Nowakowskiella (Cladochytriaceae, Chytridiomycota) en ambientes de la pcia. De Buenos Aires (Argentina): taxonomía, frecuencia y abundancia de las especies encontradas. Boletín de la Sociedad Argentina de Botánica, 42(1-2): 13-24.

Marano VA, Barrera MD, Steciow MM, Donadelli JL and Saparrat MCN. 2008. Frequency, abundance and distribution of zoosporic organisms from las canãs stream, Buenos Aires, Argentina. Mycologia, 100(5): 691700 .

Martel A, Sluijs ASD, Blooi M, Bert W, Ducatelle R, Fisher MC, Woeltjes A, Bosman W, Chiers K, Bossuyt, F and Pasmans F. 2013. Batrachochytrium salamandrivorans sp. Nov. Causes lethal chytridiomycosis in amphibians. Proceedings of National Academy. 110(38):15325-15329.

Milanez AI, Trufem, SFB. 1984. Fungos zoospóricos em frutos submersos no Parque Estadual das Fontes do Ipiranga. Rickia 11:77-84.

Milanez AI. 1989. Distribuição de fungos de águas continentais. In: Fidalgo, bononivl (coords), Técnicas de coleta, preservação e herborização de material botânico. Série documentos. Instituto de botânica São Paulo, Brasil, 17-20.

Nascimento CA and Pires-Zottarelli CLA. 2009. Chytridiales (Chytridiomycota) do Parque estadual da Serra da Cantareira. Acta Botânica Brasilica, 23:459-473.

Nascimento CA, Pires-Zottarelli CLA. 2010. Blastocladiales e Spizellomycetales from the Parque estadual da Serra da Cantareira, São Paulo, São Paulo state, Brazil. Brazilian Journal of Botany, 33(4): 693-704.

Nascimento CA, Gomes EPC and Pires-Zotarelli CLA. 2011. Occurrence and distribution of zoosporic organisms in water bodies from Brazilian cerrado. Mycologia, 103(2): 261-272.

Nascimento CA and Pires-Zottarelli CLA. 2012. Diversidade de fungos zoospóricos da reserva biológica de Mogi Guaçu, estado de são Paulo, Brasil. Rodriguésia, 63(3): 587-611.

Ohki T, Akita F, MochizukiT, Kanda A, Sasaya T and Tsuda S. 2010. The protruding domain of the coat protein of melon necrotic spot virus is involved in compatibility with and transmission by the fungal vector Olpidium bornovanus. Virology, 402(1): 129-134.

Porter TM, Martin W, James TY, Longcore JE, Gleason FH, Adler PH, Letcher PM and Vilgalys R. 2011. Molecular phylogeny of the Blastocladiomycota (Fungi) based on nuclear ribosomal DNA. Fungal Biology, 115(4): 381-392.

Pires-Zottarelli CLA. 1990. Levantamento dos fungos zoospóricos da represa do lobo ("broa"), São Carlos - SP. 
Dissertação de mestrado. Universidade Estadual Paulista, Rio Claro, São Paulo.

Pires-Zottarelli CLA. 1999. Fungos zoospóricos dos vales dos rios Moji e Pilões, região de Cubatão, São Paulo, SP, Brasil. Tese de doutorado. São Paulo: Universidade Estadual Paulista, Rio Claro, SP.

Pires-Zottarelli CLA and Gomes AL. 2007. Contribuição para o conhecimento de Chytridiomycota da Reserva Biológica de Paranapiacaba, Santo André, SP, Brasil. Biota Neotrópica, 3: 309-329.

Pires-Zottarelli CLA and Rocha M. 2007. New records of Chytridiomycota and Oomycota from the Parque Estadual das Fontes do Ipiranga, SP, Brazil. Acta botanica brasilica, 21(1): 125-136.

Prefeitura municipal de Teresina. 2010. Perfil de Teresina: econômico, social, físico e demográfico: secretaria municipal de desenvolvimento econômico e turismo - SEMDEC. 112p.

Rocha JRS. 2002. Fungos zoospóricos em área de cerrado no Parque Nacional de Sete Cidades, Piauí, Brasil. Tese de doutorado. Universidade de São Paulo, São Paulo, SP.

Rocha JRS, Sousa NDC, Macêdo, MAM, Saraiva LS, Santos LA, Sousa, ALM, Costa MFV, Sales PCL, Cronemberger AA, Gomes AS, Rodrigues EP, Barros BSV, Sousa, LMA and Silva DFM. 2015. First records of Monoblepharella taylori sparrow (Monoblepharidales) in Brazil. Current research in environmental \& applied mycology, 5(1): 74-77. 2015.

Rocha JRS, Saraiva LS, Silva JB and Macêdo MAM. 2016. The genus Allomyces (Blastocladiomycota) in the Setate of Piauí, Brazil. Hoehnea, 43(3), 487-495.

Rocha M and Pires-Zottarelli CLA. 2002. Chytridiomycota e Oomycota da represa de Guarapiranga, São Paulo, SP. Acta Botanica Brasílica, 16: 287-309.

Secretaria de meio ambiente e recursos hídricos do Piauí. Bacia do rio Poti. 2004. Atlas de abastecimento de água do estado do Piauí.

Shearer CA, Descals E, Kohlmeyer B, Kohlmeyer J, Marvanová L, Padgett D, Raja HA, Schmit JP, Thorton HA and Yoglymayr H. 2007. Fungal biodiversity in aquatic habitats. Biodiversity conservation, 16: 49-67.

Sparrow Jr FK. 1960. Aquatic phycomycetes. University of Michigan press, ann arbor, 2 ed.

Steciow MM, Milanez AI, Pires-zottarelli CLA, Marano AV, Letcher, PM and Vélez CG. 2012. Zoosporic true fungi, heterotrophic straminipiles and plasmodiophorids: status of knowledge in south america. Darwiniana, 50(1): 25-32.

Toledo LF, Britto FB, Araújo OG, Giasson LM, Haddad CF. 2006. The occurrence of Batrachochytrium dendrobatidis in Brazil and the inclusion of 17 new cases of infection. South American jornal of Herpetology, 1(3): 185191.

Trindade Jr OC. 2013. Riscos socioambientais e diversidade de fungos zoospóricos em lagoas de Teresina, Piauí. Dissertação de mestrado. Universidade Federal do Piauí, Teresina, PI, Brasil. 
Zak JC and Willig MR. 2004. Fungal biodiversity patterns in: Mueller, g.m.; bills, g.f.; foster, m.s. (eds.) biodiversity of fungi. Elsevier academic press,59-75. 